
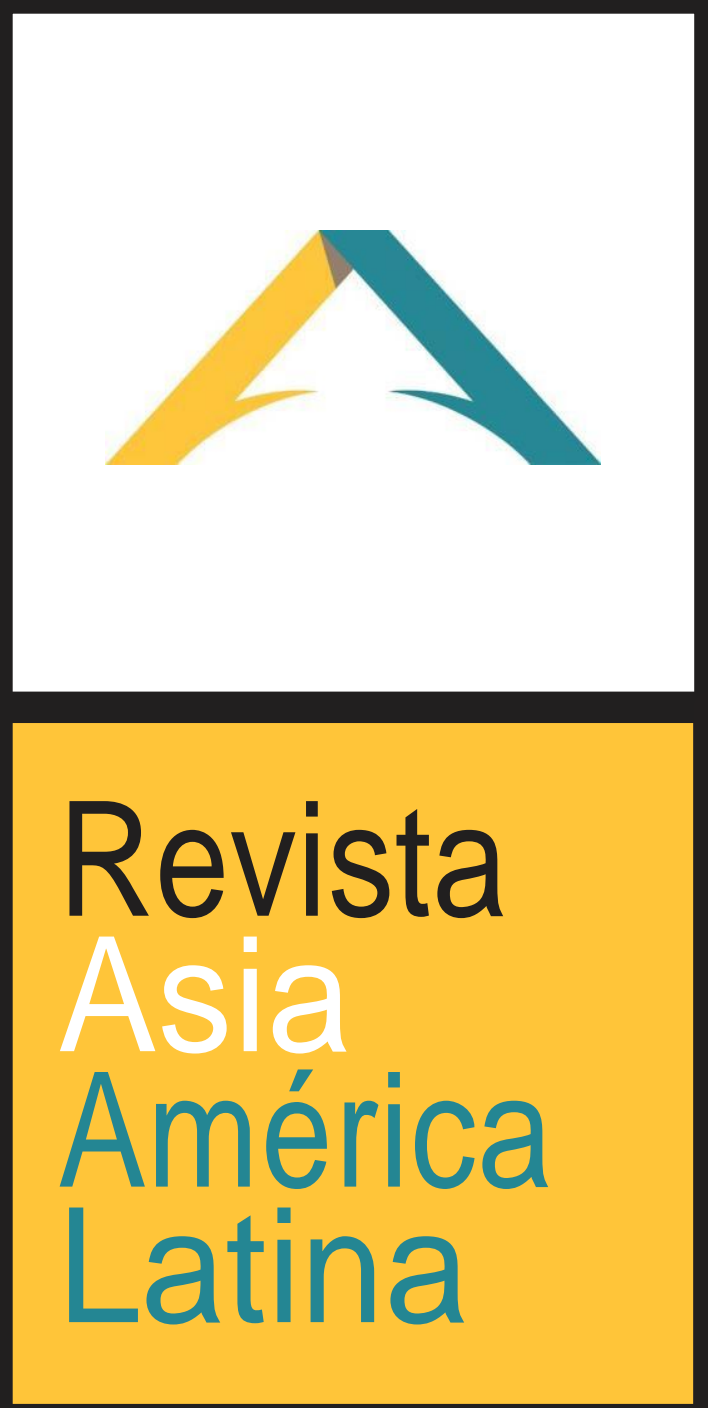

ISSN 2524-9347

Grupo de Estudios sobre Asia y América Latina Instituto de Estudios de América Latina y el Caribe Universidad de Buenos Aires

EU

DE BA 


\section{DAVID ALMAZÁN TOMÁS, COORDINADOR. JAPÓN Y EL AGUA: ESTUDIOS DE PATRIMONIO Y HUMANIDADES}

Prensas de la Universidad de Zaragoza, 2018.

\section{José Pazó Espinosa}

Universidad Autónoma de Madrid

El agua siempre ha estado siempre muy presente en la cultura japonesa. Por su condición de archipiélago, por su clima — con una temporada de lluvias intensas-y por el hecho de que las aguas termales proliferan por las montañas y valles de su orografía. Todos los aspectos de su vida cotidiana pasan por esta relación, sea en la gastronomía, el aseo, el folklore o las artes. Centrándose en esta relación, la editorial Prensas de la Universidad de Zaragoza presentó en el año 2004 el libro Japón: Arte, cultura y agua. David Almazán, participante ya en aquel proyecto, retoma ahora esta idea central y nos presenta Japón y el agua: estudios de patrimonio y bumanidades, del que él mismo nos dice en la introducción que comparte algunos autores con aquel, si bien otros han desaparecido por el camino. Se podría decir que el agua permanece y sigue fluyendo bajo los puentes hispanojaponeses, a pesar de la inevitable sucesión de primaveras.

El libro se divide en dos partes: la primera, recoge artículos sobre literatura, traducción y música; la segunda, sobre arte y cine de animación. Y siempre con temas que incluyen al agua como elemento común. El libro se abre con un texto de Mizuho Narita, profesora de la Universidad de Estudios Extranjeros de Kobe, titulado "¿Cómo suena el agua en las obras de la literatura japonesa? Estudio comparativo de la traducción literaria." Como la misma autora indica, en el idioma japonés hay un número enorme de onomatopeyas. Sin embargo, no son onomatopeyas en el sentido que se le da al término en español o en otras lenguas occidentales. En la tradición occidental, la onomatopeya es una unidad léxica icónica que imita un sonido, es decir, un significante cuyo significado es el propio sonido natural o artificial. Sin embargo, en Japón existen palabras que denotan sonidos de seres animados (giseigo, 擬声語), sonidos de objetos inanimados y de la naturaleza (giongo, 擬音語), estados de ánimo (gitaigo, 擬態語), movimientos y desplazamiento (giyougo, 擬容語), y sentimientos (gijougo, 擬情語). En definitiva, en japonés hay unidades léxicas, palabras consideradas onomatopéyicas que reflejan cualquier sensación, empezando por las de los sentidos, para pasar a sensaciones psicológicas. En consecuencia, el número de onomatopeyas en inglés es simplemente enorme comparada con el 
español, lengua en el que los fenómenos de fonosimbolismo son más reducidos, lo que supone un problema a la hora de traducirlas.

La profesora Narita se centra, en su trabajo, en la traducción de las onomatopeyas de agua en diversos géneros literarios: el comic, el haiku y la novela. En este último caso, analiza casos de onomatopeya en obras de la interesante autora Hiromi Kawakami (1958-). En ellas, a partir de las expresiones さやさや (ruido de roce de cosas finas) 、ちゃぷちゃぷ (ruido de chapoteo) 、

しみしみ (creada por Kawakami, indica algo pegajoso), ven la necesidad en el traductor de elaborar la imagen del texto para poder transmitir el significado del texto original.

Del sonido del agua, pasamos a la recepción de la obra de Ichiyo Higuchi en el círculo literario inglés de 1896, en concreto a su relato "Aguas turbulentas". Pilar Garcés hace un análisis en clave feminista sobre la obra de Higuchi, en el que, más que ver el efecto de la obra de esta autora en Europa, establece una relación de sensibilidades con un amplio espectro de autores y autoras europeos. A este capítulo, le sigue otro titulado "Arquetipo femenino, punto de vista masculino: el agua en Komachi hensô”, en el que Irene Starace, basándose principalmente en Bachelard, analiza el arquetipo del agua dentro de la novela de Enchi Fumiko de 1965 Komachi Hensô (El disfraz de komachi). Llega a la conclusión de que funciona como símbolo de lo femenino, pero desde un punto de vista masculino, es decir, incluso en el caso de Enchi, el agua es un símbolo creado desde la otredad, de género en este caso.

A continuación, se enlazan dos ensayos sobre el agua en la obra de la novelista Yoko Tawada, y en concreto sobre su obra El baño (publicado originalmente en alemán en el año 1989). Tawada es una novelista nipona particular, que vive en Berlín y escribe tanto en japonés como en alemán. Es, en ese sentido, una representante contemporánea de la literatura exofónica, literatura de autores que han preferido escribir en otra lengua que la suya materna. En primer trabajo, de Jesús Pérez García, titulado "Construcción del sujeto femenino a través del ritual del aseo u ofuro en Yoko Tawada, El baño", al autor relaciona la autoimagen y la percepción del otro con el aseo y la higiene, desde el punto de vista de la hipersensibilidad y de la eliminación de la distinción sexual a través de una archicreación de lo femenino como entidad epicena. A este trabajo le sigue otro de Nuria Ruiz Morillas, "El agua como medio para expresar las transformaciones de identidad. Un análisis interdisciplinar de El baño, de Yoko Tawada". En él, argumenta que el agua sirve a la autora para establecer una metáfora entre las cualidades cambiantes del agua y las de la identidad de la protagonista. El agua se convierte así en símbolo de la transformación identitaria de la mujer contemporánea.

Tras la identidad, pasamos a los paisajes del agua descritos por viajeros hispanohablentes por Japón, en concreto al capítulo titulado "Los paisajes del 
agua de Japón. Dos visiones en los relatos de viajeros hispanos en la era Meiji (1868-1912)". En concreto, Elena Barlés analiza los testimonios del diplomático Francisco de Reynoso y del escritor Enrique Gómez Carrillo. Barlés recupera las memorias del primero, y busca en ellas, como si de la descripción de un objeto de arte se tratara, lugares artísticos de Japón relacionados con el agua y visitados por Reynoso. Las descripciones de Carrillo, poeta y observador cuidadoso están además llenas de comentarios sobre la significación y trascendencia de esos paisajes para los japoneses. En definitiva, el apunte de viajes de ambos es descripción, pero también écfrasis y ontología del Otro al que se quiere conocer.

Cierran esta primera parte del libro dos capítulos sobre literatura, el primero de carácter a la vez antiguo y contemporáneo ya que en él Lourdes Terrón Borbosa se centra en la vida y obra de Miyamoto Musashi, el samurái santo o kensei, que se convirtió en una leyenda todavía en vida por su dominio de la espada y por su obra Gorin no sho o Libro de los cinco anillos, recientemente publicado en la editorial Satori. El novelista Eiji Yoshikawa (1892-1962) lo tomó como modelo para el protagonista de una de sus novelas históricas y creo así el arquetipo moderno del samurái. La novela se llamó Musashi. La leyenda del samurái: tierra, agua, fuego, y tuvo un éxito inmenso en Japón. Sobre ella se hicieron películas y series de televisión. El segundo libro de la novela, dedicado al agua, establece un símil entre la mentalidad del samurái y el agua, con iguales capacidades adaptativas y de fluidez. La autora del capítulo lo compara después con Les samouraïs, de Julia Kristeva, novela sobre los círculos literarios franceses del mayo del 68. La autora acaba haciendo una reflexión sobre el fluir del agua y el fluir del tiempo, con referencias a la cultura zen. El siguiente y último capítulo de esta primera parte, trata de la novela de Mishima Yukio El marino que perdió la gracia del mar (1963) y de sus adaptaciones musicales por el autor de teatro lírico Hans Werner Henze. El autor del capítulo defiende que Henze efectuó una adaptación de las sensibilidades japonesas, con un énfasis en el budismo y en la naturaleza como locus poeticus, es decir, en el sintoísmo. Henze mezcla elementos operísticos con matices japoneses, integrando el ritmo de la lengua japonesa, de forma que hasta se acerca al kabuki. Sin embargo, evita caer en orientalismos y exoticimos presentes en obras líricas anteriores.

La segunda parte del libro se inicia con artículo de David Almazán sobre Hokusai y sus mil vistas del mar, su serie muy poco conocida del año 1833 Chie no umi. Tras una breve introducción, Almazán define a Hokusai como el pintor japonés del mar, sobre todo por esta serie, que podemos también traducir como mil vistas del océano. A pesar de su título, la serie se compuso en realidad por solo diez estampas, que Almazán analiza con detalle a menudo esclarecedor. Solo resta algo de valor a su contemplación, el hecho de que estén reproducidas en blanco y negro, perdiéndose la constatación de los detalles que Almazán relata en sus amenas écfrasis. La conclusión del autor es que esta serie es tan valiosa como otras mucho más conocidas del mismo Hokusai. Sin duda esta exposición 
puede servir para situar esta obra marina en el punto de mira de futuras investigaciones.

El segundo capítulo de esta parte tiene por título "El agua en la cerámica Satsuma" y está firmado por David Lacasta Sevillano. Lacasta hace una introducción histórica para centrar la relevancia de Satsuma y la influencia coreana en este dominio. Después, analiza los motivos decorativos y establece lazos entre la tradición marítima del dominio y los motivos que aparecen en las piezas cerámicas, apuntando también la influencia de los paisajes que aparecen las cerámicas en el orientalismo de los siglos XIX y XX. Tras este trabajo, Carolina Plou analiza los lagos, jardines, cascadas, mares y espacios acuáticos en general representados en la fotografía Meiji a través de las colecciones españolas. Se trata, por tanto, de una puesta en valor de ese patrimonio que muchas veces duerme el suelo de los justos. La fotografía tuvo en Japón en la época Meiji una eclosión particular. Se trata de fotografía paisajística, pero también de fotografía de estudio realizada con fondos artísticos artificiales que recreaban condiciones atmosféricas de lo más variadas. La autora busca el sentido y el significado de esos elementos acuáticos en los retratos de esta época ya moderna, y encuentra relaciones con la tradición y con el pasado.

A continuación, Alejandra Rodríguez Cunchillos trata la presencia del agua en la obra del artista japonés contemporáneo Ikeya Tomohide (1974-). Se centra en fotografías suyas, en particular en la serie Wave Serie y en Moon Serie, que remiten inequívocamente al también fotógrafo Araki Nobuyoshi y sus series sobre el shibari, o atado de seres humanos con sogas. Tienen, sin duda, la misma relación entre vida y muerte, placer y dolor. Por último, analiza la Breath Serie del autor, figuras humanas submarinas, a veces repeliendo diminutas burbujas, que enlazan con las ideas y conceptos anteriores. La autora pone en valor y contexto estas obras, interesantes y contemporáneamente tradicionales.

El siguiente trabajo, de Iratxe Hernández Simal, y se centra en la performance The Play Have a House, que se llevó a cabo por primera vez en el año 1972. Consistió en un viaje fluvial de cinco días sobre una casa flotante que reproducía la descripción de Kamo no Chômei sobre su cabaña en el Hôjôki (1212). La autora analiza las conexiones de la performance con el budismo, el mundo flotante y el fluir del Tao. A continuación, pasa a la escultura de niebla llamada "Fog Sculpture" (1998) de Nakaya Fujiko. Del fluir del río pasamos a la indeterminación de la niebla, al desdibujado de los contornos, también con abundantes connotaciones tradicionales. De ahí a Maruyama Shinichi y sus cuerpos suspendidos en el espacio, que resultan de arrojar líquido desde la altura. Lo relaciona con la belleza de lo imperfecto y los principios estéticos del zen. De ahí a los Seascapes de Hiroshi Sugimoto, famosas fotografías de mar y cielo, que culminaron con su fundación, que parece querer abrazar cielo y mar. Y de las fotografías del mar, pasamos a los sonidos de Tomoko Sauvage, basados en el agua congelada, las resonancias del hielo, y a las instalaciones inmersivas de 
Shiota Chiharu, y sus universos tejidos por hilos que crean nidos y telas de araña, refugios y lugares de peligro.

Los dos últimos capítulos tratan sobre el agua en el anime japonés y el agua en el cine de Miyazaki Hiyao. El primero, de Claudia Bonillo Fernández, trata la serie Tetsuwan Atomu (brazo de acero atom) (1963) de Tezuka Osamu. La autora del capítulo destaca el agua como vía de expresión de emociones, tanto positivas como negativas. Se diría que el agua es un elemento no marcado, que acepta distintas polaridades. Sigue analizando series más actuales, siempre con esta relación entre agua y emoción. Sin embargo, también pone de manifiesto otros usos semióticos, tales como su relación con fantasmas, como puente de conexión entre mundos o como simplemente puerta a otro mundo. En el último capítulo, Raúl Fortes Guerrero caracteriza el agua en la obra de Miyazaki como marco contextualizador, como dispositivo narrativo, como elemento simbólico general y de la condición psicológica de los personajes en particular, como símbolo vinculado a la mitología y a la religión, como elemento de unión con el pasado y la tradición. Parecen claras en la obra de Miyazaki las referencias al budismo, al sintoísmo, al taoísmo y a la historia mítica del Japón viejo.

En definitiva, el libro en su conjunto se trata de una obra variada, amena a pesar de su naturaleza académica, y sugerente en muchas maneras, muy proclives a futuras investigaciones y a nuevas variaciones sobre el mismo tema. En Japón, los elementos básicos, agua, fuego, tierra, aire tienen todavía una carga simbólica muy presente en la vida diaria. A diferencia de otras culturas cuyo discurso se ha visto más influido por el logos y la ciencia de la Ilustración, Japón conserva esos hilos que ligan el hoy con el pasado, la técnica con la artesanía, la ciencia con la magia y la religión. Este libro, en ese sentido, ayuda a hacer más visible lo invisible y más cercano lo lejano. 

